\title{
Long-term follow-up after surgical removal of thymolipoma
}

\author{
Mahnaz Amini ${ }^{1}$, Seyed Hossein Fattahi Masuom², Asieh Sadat Fattahi ${ }^{2}$ \\ ${ }^{1}$ Lung Diseases Research Center, Mashhad University of Medical Sciences, Mashhad, Iran \\ 2Endoscopic and Minimally Invasive Surgery Research Center, Mashhad University of Medical Sciences, Mashhad, Iran
}

Kardiochir Torakochir Pol 2019; 16 (4): 206-208

The thymus is the largest lymphoid tissue of the human body, located in the superior mediastinum, growing until puberty and then involuting to nearly disappear around 18 years [1]. It can be affected by benign and malignant neoplasms. Thymolipoma, comprising 2-9\% of thymic neoplasms, is a rare benign neoplasm of the thymus composed of mature adipose and thymic tissue [1]. Less than 200 cases had been reported in the literature by 2015 [2]. Although rare, it should be considered in the differential diagnosis for any anterior mediastinal mass with fat density.

A 22-year-old man was admitted to Ghaem teaching hospital, Mashhad, Iran with 3 months history of dyspnea on exertion and chest heaviness. He had no other chest, constitutional symptoms or signs of autoimmune disorders. On physical examination the only abnormal finding was complete absence of vesicular breath sounds in the left hemithorax. Posteroanterior chest radiograph revealed a huge fat density obscuring the left heart and mediastinal border (Figure 1).

Chest computed tomography (CT) showed a large mass $(22 \times 19 \times 17 \mathrm{~cm})$ with fat density admixed with soft tissue strands occupying the anterosuperior mediastinum extending to the left hemithorax (Figure 2). Laboratory tests were not remarkable. The patient was scheduled for surgical resection with a primary diagnosis of thymolipoma. Care was taken as regards malacia or external pressure of the left main bronchus. Partial sternotomy was accompanied with left thoracotomy through the fifth left intercostals space. The tumor $(31 \times 15 \times 12 \mathrm{~cm})$ resided left of the pericardium without any invasion to pericardial or lung tissue (Figure 3). Dehiscence of the tumor by blunt and sharp dissection was easily done with care about preservation of the left phrenic nerve.

A large encapsulated tumor with a yellowish elastic surface and soft yellowish fatty tissue by incision was removed (Figure 4). Histopathological examination revealed mature adipose tissue and hyperplastic thymic structures with Hassel's corpuscles identified as a benign thymolipoma.

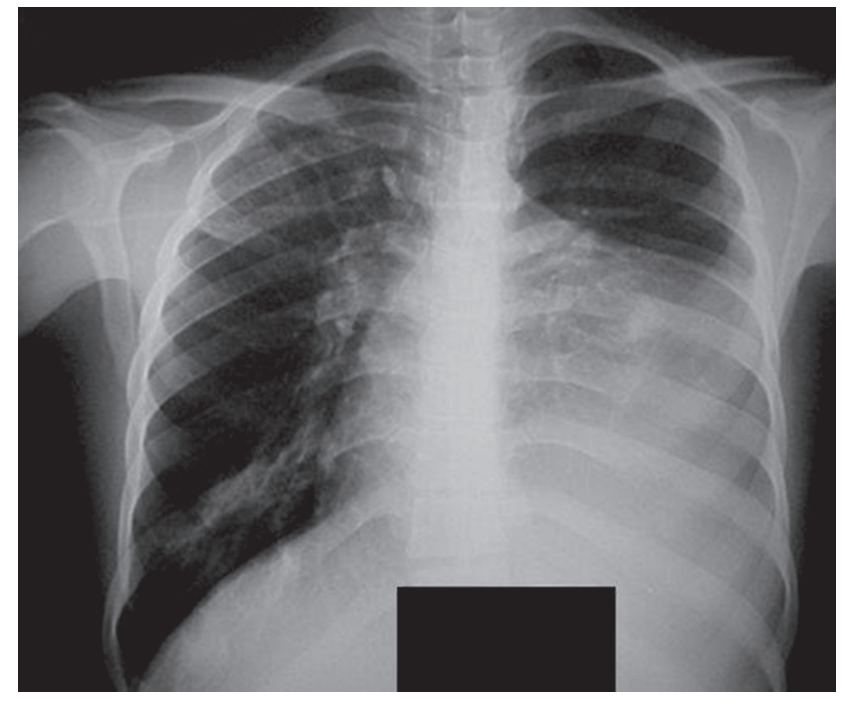

Figure 1. Chest radiograph of the case showing huge mass with fat density in left hemithorax obscuring left heart border

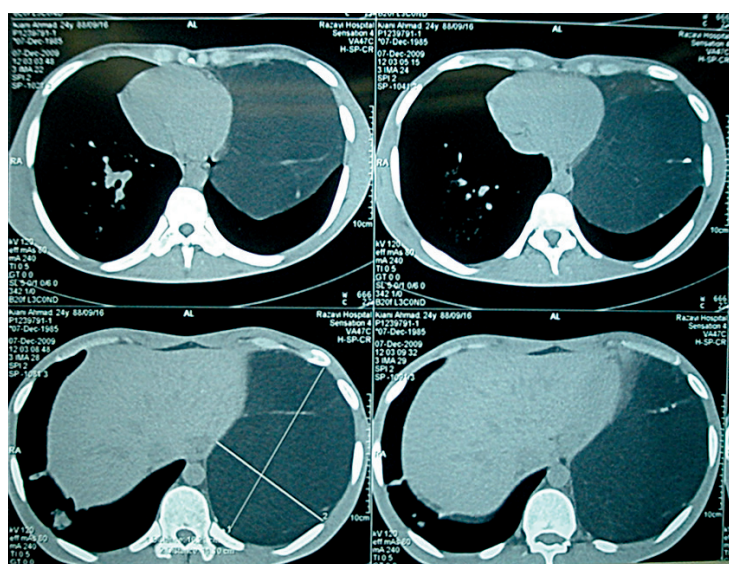

Figure 2. Chest computed tomography of the case representing huge left mass comprising fat density with strands of soft tissue density with mild compressing effect on the heart pushing it to the right

Address for correspondence: Assoc. Prof. Asieh Sadat Fattahi, Endoscopic and Minimally Invasive Surgery Research Center, Mashhad University of Medical Sciences, Mashhad, Iran phone/fax: +98 5138402972, e-mail: emis@mums.ac.ir Received: 22.09.2019, accepted: 12.11.2019. 


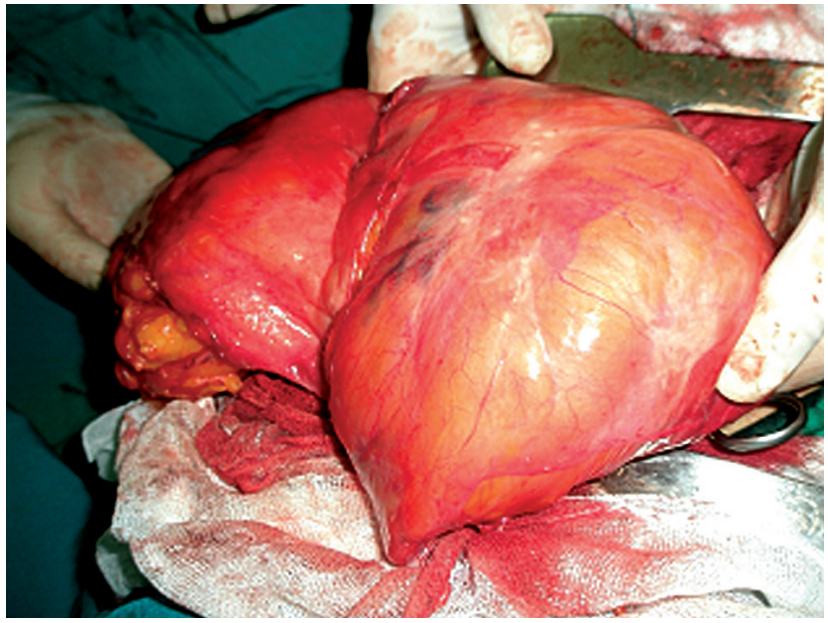

Figure 3. Intra-operative view of soft encapsulated large mass removed totally via left thoracotomy

The postoperative period was uneventful, and the patient was discharged on the $5^{\text {th }}$ postoperative day with good general condition. Frequent yearly visits until 10 years showed no symptom or sign of recurrence or any clue in favor of autoimmune disorders.

Lange reported the first case of thymolipoma in 1612, but the term of thymolipoma was used many years later by Eid et al. in 2017 [3]. Thymolipoma is a rare benign neoplasm of the thymus of unknown etiology representing $2-9 \%$ of thymic neoplasms with no known predilection to specific age or sex.

Many different pathogenic mechanisms have been proposed for thymolipoma [4], from replacement of the thymus with mature adipose tissue, involuting thymic hyperplasia, mixed tumor theory and involuting thymoma theory. Thymolipoma shows a slow insidious growth with most of the reported cases presenting as huge masse before diagnosis.

Patients are usually asymptomatic, but most patients complain of vague symptoms in the chest because of compression of fatty tissue on adjacent structures including the heart, the great vessels, the lungs or the bronchi [5] with reports of respiratory distress or failure $[6,7]$. They can be even incidentally found and misdiagnosed as a large cardiac silhouette in chest radiograph [8].

As in the case of thymoma, thymolipoma can present with some autoimmune disorders such as myasthenia gravis, systemic lupus erythematosus, hypogammaglobulinemia, Graves' disease and red cell aplasia (RCA) [9]. Huang et al. studied 267 patients with MG who underwent extended thymectomy, with 12 (4.4\%) patients showing thymolipoma in the pathologic study. Compared with myasthenic thymoma, myasthenic thymolipoma had longer preoperative duration of symptoms and larger mass. Compared with non-myasthenic thymolipoma patients, myasthenic thymolipoma patients were older with smaller masses which were diagnosed after surgery [10].

Characteristic CT findings include a usually huge mass originating from or connected to the thymus gland with fatty tissue and soft tissue strands as islands of normal

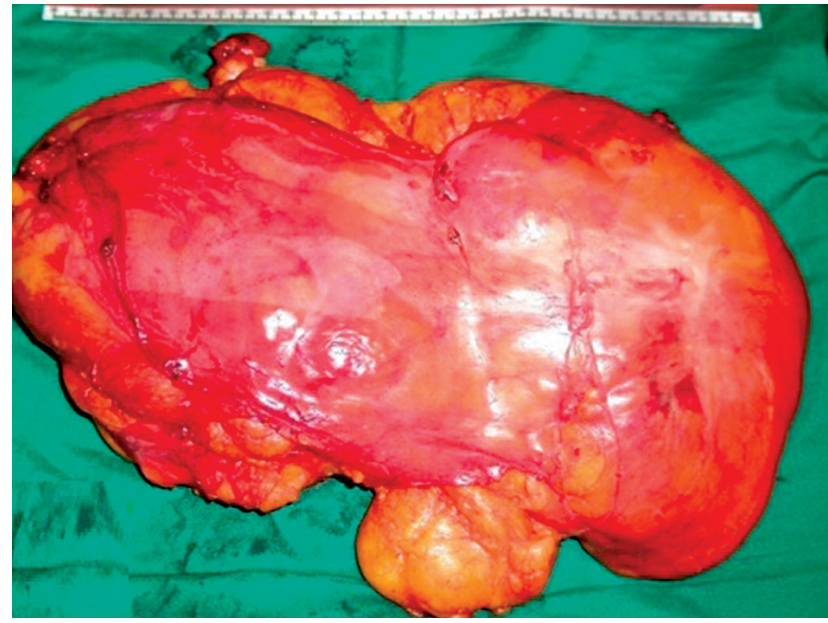

Figure 4. Excised soft encapsulated mass $(31 \times 15 \times 12 \mathrm{~cm})$

thymic components [11]. The main differential diagnoses of thymolipoma in imaging are lipoma, liposarcoma, teratoma, pericardial fat pad or diaphragmatic hernias [12]. Magnetic resonance imaging (MRI) scans are specific for high signal intensity mixed with intermediate intensity on T2-weighted images. Adipose tissue of the tumor is intense in T1-weighted images [13].

As thymolipoma is a benign neoplasm with no reported case of recurrence, its main treatment is complete surgical removal. Preoperative tissue diagnosis with biopsy is not usually needed. The surgical approach to resection of thymolipoma is through sternotomy, anterolateral thoracotomy, clamshell incision or sternotomy accompanied by anterolateral thoracotomy (hemi-clamshell incision).

The natural course of thymolipoma after surgical removal is usually uneventful [14]. Rieker et al. reported 5 -year follow-up after surgical removal of thymolipoma in 9 cases. All their patients were free of symptoms 5 years after surgery [9].

To the best of our knowledge this is the first case of thymolipoma surgical treatment with 10 years' symptom-free follow-up. Our patient had no sign of recurrence or autoimmune disorders after about one decade, emphasizing the benign nature of thymolipoma.

This is one of the longest symptom-free survival reports of thymolipoma after surgical removal with about one decade of no complaints or autoimmune symptoms. This case report emphasizes the benign nature of thymolipoma after surgical removal even after many years.

\section{Disclosure}

The authors report no conflict of interest.

\section{References}

1. Nishino M, Ashiku SK, Kocher ON, Thurer RL, Boiselle PM, Hatabu H. The thymus: a comprehensive review. Radiographics 2006; 26: 335-348.

2. Premananth P, Dhanasekar T, Baby MK, Rajagopalan B. Thymolipoma: a rare, large anterior mediastinal mass. J Evol Med Dental Sci 2015; 4: 10556-10562. 
3. Eid HA, Ali AE, Elsabry MA. Enormous thymolipoma: a case report. Egypt J Bronchol 2017; 11: 165-167.

4. Mourad OM, Andrade FM, Abrahão P, Monnerat A, Judice LF. Asymptomatic giant mediastinal mass: a rare case of thymolipoma. J Brasil Pneumol 2009; 35: 1049-1052.

5. Moschos C, Kalomenidis I, Roussos C, Stathopoulos GT. A 35-year-old male with chronic cough. Eur Respir J 2007; 29: 608-611.

6. Roque C, Rodríguez P, Quintero C, Santana N, Hussein M, Freixinet J. Giant thymolipoma. Arch Bronconeumol 2005; 41: 402-403.

7. Dongel I, Imamoglu H, Şahin AF, Yıldırım S, Bayram M. A rare mediastinal tumor: thymolipoma. Eur J General Med 2014; 11 (Suppl 1): 21-23.

8. Ceran S, Tulek B, Sunam G, Suerdem M. Respiratory failure caused by giant thymolipoma. Ann Thor Surg 2008; 86: 661-663.

9. Rieker RJ, Schirmacher P, Schnabel PA, Moser K, Hoffmann H, Dienemann H, Pfannschmidt J. Thymolipoma. A report of nine cases, with emphasis on its association with myasthenia gravis. Surgery Today 2010; 40: 132-136.
10. Huang CS, Li WY, Lee PC, Kao KP, Chou TY, Wu MH, Hsu HS, Wu YC, Hsu WH, Huang BS. Analysis of outcomes following surgical treatment of thymolipomatous myasthenia gravis: comparison with thymomatous and non-thymomatous myasthenia gravis. Inter Cardiovasc Thorac Surg 2013; 18: 475-481.

11. Bogot NR, Quint LE. Imaging of thymic disorders. Cancer Imaging 2005; 5: 139-149.

12. Vaziri M, Rad K. Progressive dyspnea in a 40-year-old man caused by giant mediastinal thymolipoma. Case Rep Surg 2016; 2016: 3469395.

13. Shirkhoda A, Chasen MH, Eftekhari F, Goldman AM, Decaro LF. MR imaging of mediastinal thymolipoma. J Comput Assist Tomogr 1987; 11: 364-365.

14. Baby MK. Thymolipoma, mediastinum, thymus, histopathological, neoplasm. Thymolipoma: a rare, large anterior mediastinal mass. 2015 Jul 27 (8521). 